\title{
AIDS, RELAÇÕES CONJUGAIS E CONFIANÇA: UM ESTUDO SOBRE REPRESENTAÇÕES SOCIAIS
}

\author{
Leandro Castro Oltramari \\ Brigido Vizeu Camargo
}

\begin{abstract}
RESUMO. Este artigo tem por objetivo compreender a influência das representações sociais da Aids na prevenção dos comportamentos de vulnerabilidade ao HIV, nas relações de conjugalidade entre homens e mulheres heterossexuais. Participaram da pesquisa 48 pessoas, sendo a metade constituída de homens e a outra metade, de mulheres. A idade variou entre 19 e 74 anos. Para a análise do material coletado foi utilizada uma classificação hierárquica descendente das narrativas (ALCESTE). Os resultados demonstraram, por meio das representações sociais da Aids, que os entrevistados tinham cuidado com pessoas de grupos sociais específicos, empregando a ideia de "grupos de risco". Além disto, os entrevistados relacionaram a Aids ao medo e ao sexo com pessoas de comportamento perigoso. Foi possível concluir, com este estudo, que o parceiro conhecido é considerado menos perigoso do que as pessoas desconhecidas. Houve uma forma específica de negação do risco por parte dos entrevistados, devido às relações estáveis.
\end{abstract}

Palavras-chave: Representação social; relações conjugais; Aids.

\section{AIDS, CONJUGAL RELATIONS AND RELIANCE: A STUDY ON SOCIALS REPRESENTATION}

\begin{abstract}
This paper has the goal of understanding how social representations of HIV influence preventive measures against this virus in conjugal relations between heterosexual men and women. Forty-eight people took part on this research, half men and half women, heterosexuals living as couples. Age ranged from 19 to 74 years. For the analysis of collected material, a descending hierarchical classification of narratives (ALCESTE) was used. Results have showed through AIDS social representations that the interviewed subjects proceeded with caution when dealing with people from specific social groups, adopting the idea of "unsafe groups". Besides, it was identified that they related AIDS to fear and sex with people who had not safe sexual behaviors. It was possible to discover, with this study, that the known partner is less dangerous than the unknown ones. There was a specific way of denial of the risk by the subjects, due to stable relationships they had.
\end{abstract}

Key words: Social representations; conjugal relations; Aids.

\section{SIDA, RELACIONES CONYUGALES Y CONFIANZA: UNA INVESTIGACIÓN SOBRE REPRESENTACIONES SOCIALES}

RESUMEN. Este artículo tiene por objetivo comprender la influencia de las representaciones sociales del SIDA en la prevención de los comportamientos de vulnerabilidad al IVH, en las relaciones de conyugalidad entre hombres y mujeres heterosexuales. Participaron de la investigación 48 personas, siendo la mitad hombres y la otra mitad mujeres. Las edades estuvieron entre 19 y 74 años. Para el análisis del material colectado se utilizó una clasificación jerárquica descendiente de las narrativas (ALCESTE). Los resultados demostraron através de las representaciones sociales del Sida, que los entrevistados tenían cuidado com personas de grupos sociales específicos, empleando la idea de "grupos de riesgo". Asimismo, se identificó que los entrevistados relacionaron el sida al miedo y al sexo com personas de comportamiento peligroso. Fue posible concluir con este estudio, que el compañero conocido es considerado menos peligroso que las personas desconocidas. Hubo una forma específica de negación del riesgo por parte de los entrevistados, debido a las relaciones estables.

Palabras-clave: Representación social; relaciones conyugales; Sida.

Doutor em Interdisciplinar em Ciências Humanas. Professor titular da Universidade do Vale do Itajaí, Brasil.

\# Doutor em Psicologia Social. Professor Associado II da Universidade Federal de Santa Catarina. Laboratório de Psicologia Social da Comunicação e Cognição, Brasil. 
Este estudo refere-se à influência das representações sociais da Aids na prevenção dos comportamentos de vulnerabilidade ao HIV, nas relações conjugais entre homens e mulheres heterossexuais. Esse tema tem-se mostrado um desafio para cientistas sociais e agentes da Saúde Pública, principalmente porque a principal curva ascendente da epidemia se encontra entre os indivíduos heterossexuais vivendo em conjugalidade (Ministério da Saúde, 2005). A conjugalidade aqui será compreendida não como relação de coabitação ou como relacionamento que suponha monogamia por parte dos participantes da pesquisa, mas como uma relação que permeia trocas afetivo-sexuais entre os envolvidos, com intenção de permanecerem juntos por determinado tempo. (Heilborn, 2004)

Uma série de trabalhos tem discutido aspectos relacionados às representações sociais da Aids (Paiva \& Amâncio, 2005; Ribeiro, Castanha, Coutinho \& Saldanha; 2005, Camargo, Barbará, Bertoldo \& 2007). Alguns destes estudos demonstraram que é comum o risco da epidemia de Aids ser atribuído aos "outros" outros grupos, outros segmentos sociais -, o que revela uma tentativa de controlar o medo da síndrome (Joffe, 1998).

Para contribuir com a pesquisa aqui realizada, é fundamental compreender como os estudos sobre a conjugalidade têm sido percebidos. As ciências sociais têm incluído as discussões sobre o amor e a conjugalidade, relacionando-os às práticas sociais (Gagnon, 2006). O amor e a conjugalidade se estabelecem a partir de uma elaboração partilhada de significados nas relações sociais, ou seja, eles acontecem em um jogo social como qualquer outra interação humana.

Isso pode ainda ser compreendido, segundo pesquisa de Valencia-Abundiz (2004), no caso de casais heterossexuais. Estes consideraram que o amor era uma garantia de confiabilidade no parceiro. Além disso, os entrevistados na pesquisa da autora revelavam que os relacionamentos eram percebidos como estáveis, garantindo a eles e elas segurança no interior dessa relação.

Ainda sobre pesquisas relacionadas à conjugalidade e prevenção, os estudos de Apostolidis e Deschamps (2003), Giacomozzi e Camargo (2003), Oltramari e Otto (2006), Maia, Guilhem e Freitas (2008) descobriram que a existência de relacionamento afetivo-sexual conferiu maior grau de segurança aos entrevistados que viviam neste tipo de relacionamento.

Este artigo tem por objetivo compreender a influência das representações sociais da Aids na prevenção dos comportamentos de vulnerabilidade ao
HIV nas relações de conjugalidade entre homens e mulheres heterossexuais.

\section{MÉTODO}

\section{Participantes}

Os participantes da pesquisa foram 48 mulheres e homens que viviam, até o momento da entrevista, em relação de conjugalidade, com duração mínima de seis meses. A idade dos entrevistados variou de 18 a 74 anos, com média de idade de 44,92 e moda de 42 . O desvio padrão foi de 15,54, o que caracteriza uma população de idades variadas. Do total dos 48 entrevistados, metade eram homens e a outra metade mulheres. Do total, 16 tinham menos de 50 anos e 8 tinham acima de 50 anos de idade. Dos 16 com idade inferior a 50 anos, 8 apresentavam curso superior completo e 8 tinham menor nível de escolaridade.

A seleção dos entrevistados deu-se pelo critério de exaustividade e por meio de contatos com as pessoas indicadas pelos informantes, método conhecido também como bola de neve ${ }^{1}$. Os homens indicaram homens para a realização da entrevista, enquanto as mulheres indicaram mulheres. Para a escolha dos entrevistados, o critério exigido foi a existência de um relacionamento conjugal com uma pessoa do sexo oposto e essa relação afetivo-sexual ter uma duração mínima de seis meses.

\section{Considerações éticas}

A presente pesquisa foi aprovada pelo comitê de ética em pesquisa da Universidade do Vale do Itajaí, respeitando a Resolução 196/96 do Conselho Nacional de Saúde.

\section{Instrumento de coleta de dados}

Utilizou-se a técnica da entrevista semiestruturada. Na primeira parte, propôs-se o tema da iniciação sexual e dos relacionamentos afetivosexuais dos entrevistados, obtendo-se uma narrativa sobre esse assunto. $\mathrm{Na}$ segunda parte da entrevista foi introduzido o tema da Aids. Além desses dois temas, foram apresentadas algumas questões de identificação dos participantes, contemplando as seguintes variáveis: a) sexo; b) idade (pessoas com idade até 50 anos e pessoas com idade superior a esta); c) escolaridade (pessoas com curso superior completo e

1 A utilização desta técnica é um fator limitador deste estudo. Não é possível realizar generalizações, devido a esse procedimento ter provavelmente homogeneizado a população pesquisada. 
pessoas sem curso superior); d) tempo de relacionamento (pessoas com relacionamentos de seis meses a 5 anos, pessoas com relacionamentos de 5 a 10 anos e pessoas que mantinham relacionamentos havia mais de 10 anos); e) utilização ou não do preservativo na primeira relação sexual.

\section{Procedimentos da entrevista}

Cada participante teve apresentada a proposta de pesquisa. Depois de apresentados aos sujeitos da pesquisa os propósitos da entrevista e o modo como seriam utilizados os dados dela provenientes, foi lido o termo de consentimento de pesquisa com seres humanos, para informação dos entrevistados. Após este procedimento, os entrevistados o assinaram. O tempo médio de duração das entrevistas foi de 35 minutos.

\section{Análise do material coletado}

As entrevistas gravadas foram transcritas. Com o material transcrito, realizaram-se análises lexicográficas e classificações hierárquicas descendentes (CHD), com o auxílio do programa informático ALCESTE. Este programa permite organizar e classificar os segmentos de textos de acordo com as semelhanças entre eles e indicar possíveis representações sociais (Camargo, 2005). Esse procedimento é realizado pelo programa em quatro etapas: a) etapa A - reconhecimento das UCIs (unidades de contexto iniciais) e separação do texto em tamanhos iguais (chamadas UCEs - unidades de contexto elementares); b) etapa B - as UCEs são agrupadas a partir da similaridade de palavras (essa divisão se dá em função das formas reduzidas dessas palavras); c) etapa $\mathrm{C}$ - o programa apresenta o Dendograma da Classificação Hierárquica Descendente, que demonstra as relações existentes entre as classes (o programa nessa etapa ainda realiza cálculos sobre cada uma das classes); d) etapa D - a partir das UCEs escolhidas em cada classe, o programa faz o cálculo das UCEs mais características, possibilitando, assim, a contextualização do vocabulário mais significativo das classes. Ele ainda fornece, no interior de cada classe, uma classificação hierárquica ascendente (CHA), a qual forma um dendograma, que possibilita a visualização das relações entre palavras, dentro de cada classe.

No primeiro corpus em vista da grande quantidade de palavras com frequência acima dessa média, foram utilizadas, para a análise, as palavras com frequência igual ou superior a 50 e com $\chi^{2} \geq 3,84$ (indicador da associação da palavra à classe com uma margem de erro $\leq 0,05$ ).
No segundo corpus como no primeiro, foram utilizadas para a análise as palavras com frequência igual ou superior a 50 e com $\chi^{2} \geq 3,84$ (indicador da associação da palavra à classe, com uma margem de erro $\leq 0,05)$.

O $\chi^{2}$ (qui quadrado) é um coeficiente estatistico que possibilita verificar a dispersão entre duas variaveis. Ele demonstra quanto os valores que são observados se distanciam do esperado, caso não haja relação entre as variáveis. Quanto menor for o $\chi^{2}$ menos as variaveis estão relacionadas.

\section{RESULTADOS}

Os resultados apresentados são divididos em duas partes. A primeira refere-se à iniciação sexual e aos relacionamentos afetivo-sexuais dos entrevistados; a segunda trata das representações sociais dos participantes sobre a Aids.

\section{Iniciação e experiências sexuais e afetivas}

Nesse primeiro corpus houve um total de 108.210 ocorrências de palavras e 7.125 palavras distintas, indicando uma média de 15 ocorrências por palavra. $\mathrm{O}$ corpus 1 foi dividido em 2.546 unidades de contexto elementares (UCEs) e a análise hierárquica descendente considerou para análise 2.006 UCEs, ou seja, 78,79\% do total das UCEs que o corpus 1 originalmente possuía. A figura 1 apresenta um dendograma com as quatro classes obtidas por meio da análise hierárquica descendente do conteúdo das entrevistas relacionado à iniciação sexual, ao relacionamento afetivo-sexual e ao uso de preservativo nas relações sexuais.

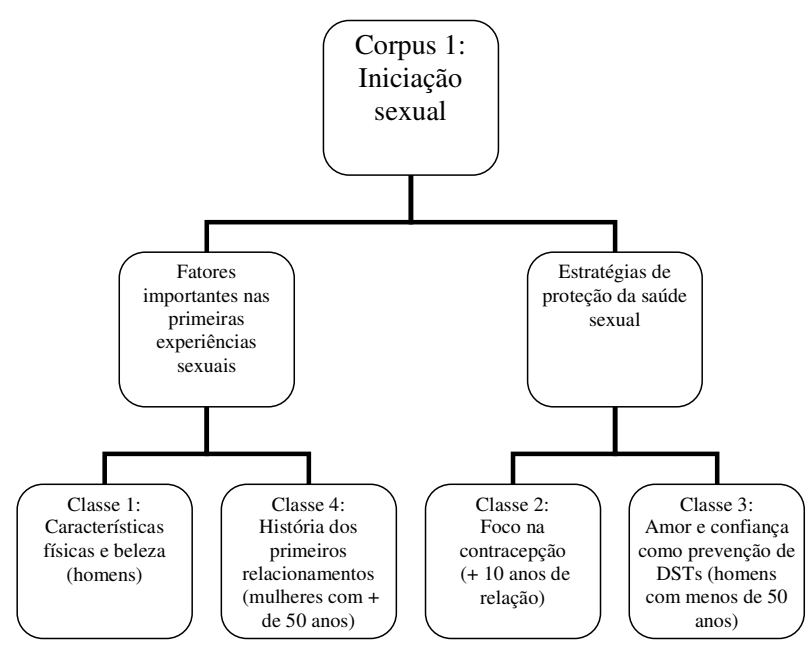

Figura 1. Classificação Hierárquica Descendente do Conteúdo das Entrevistas Sobre a Iniciação Sexual e o Relacionamento Afetivo e Sexual (n=48). Florianópolis, 2006. 
Segundo a figura 1, as classes 1 e 4 foram formadas a partir das narrativas sobre a iniciação sexual e as histórias dos primeiros relacionamentos amorosos dos entrevistados. As classes 2 e 3, por sua vez, referiram-se mais aos métodos contraceptivos e às concepções de confiança e amor no relacionamento afetivo-sexual.

Tabela 1. Conteúdo das Classes Sobre o Tema da Iniciação Sexual e o Relacionamento Afetivo e Sexual (Síntese, $n^{\circ}$ de UCE e Palavras Associadas).

\begin{tabular}{|c|c|c|c|}
\hline Classe & Síntese & $\mathrm{UCE}(\%)$ & Palavras associadas (frequência $^{2} ; \chi^{2}$ ) \\
\hline 1 & $\begin{array}{l}\text { A iniciação sexual se dá através da } \\
\text { escola, possui características corporais } \\
\text { e começa através da amizade. }\end{array}$ & $\begin{array}{c}423 \\
(21,09 \%)\end{array}$ & $\begin{array}{l}\text { anos }(130 ; 162,95), \\
\text { namorado }(274 ; 118,23), \\
\text { época }(163 ; 56,82), \\
\text { primeira }(135 ; 47,46) \\
\text { menina }(130 ; 131,55)\end{array}$ \\
\hline 4 & $\begin{array}{l}\text { Histórias de referência do início de } \\
\text { relacionamento amoroso }\end{array}$ & $\begin{array}{c}630 \\
(31,41 \%)\end{array}$ & $\begin{array}{l}\text { casa }(354 ; 91,54) \text {, dia }(220 ; 74,07) \text {, mãe }(128 ; \\
39,17) \text {, morava }(120 ; 32,98) ; \text { ficar }(374 ; 21,50) \text {; } \\
\text { estava }(306 ; 31,42) \text {, falei }(262 ; 14,55) \text {, disse } \\
(221 ; 124,39) \text {, passava }(160 ; 11,08) \text {, chegou } \\
(152 ; 50,94) \text {, ia }(133 ; 51,81) .\end{array}$ \\
\hline 2 & $\begin{array}{l}\text { Utilização de métodos de contracepção } \\
\text { na primeira relação sexual }\end{array}$ & $\begin{array}{c}243 \\
(12,11 \%)\end{array}$ & $\begin{array}{l}\text { Camisinha }(84 ; 350,79) \\
\text { médico }(57 ; 98,47) \\
\text { pensar }(142 ; 6,84) \\
\text { transar }(69 ; 66,03) \\
\text { tomar }(60 ; 98,71)\end{array}$ \\
\hline 3 & $\begin{array}{l}\text { O relacionamento afetivo-sexual como } \\
\text { uma interação entre confiança e amor }\end{array}$ & $\begin{array}{c}710 \\
(35,39 \%)\end{array}$ & $\begin{array}{l}\text { Coisa }(455 ; 57,41) \text {, pessoa }(310 ; 52,85) \text {, vezes } \\
(200 ; 14,24) \text {, relacionamento }(176 ; 47,38) \text {, } \\
\text { mulher }(159 ; 11,62) \text {, vida }(124 ; 15,20) \text {, acho } \\
(413 ; 44,58) \text {, dizer }(215 ; 16,49), \text { sei }(172 ; \\
18,98) \text {, vai }(168 ; 26,50) \text {, pensar }(142 ; 8,21) \text {, } \\
\text { tenho }(133 ; 33,68) \text {, pode }(111 ; 11,65) \text {. }\end{array}$ \\
\hline
\end{tabular}

Conforme a tabela 1 , a classe 1 esteve mais relacionada à importância das características físicas nas primeiras experiências sexuais e amorosas dos sujeitos. Isso ficou mais aparente nas respostas dos homens, principalmente daqueles com mais de 50 anos de idade. Essa classe teve média significância, pois obteve $21,09 \%$ das UCEs analisadas. A beleza física apareceu especificamente com características de pessoas "brancas". Esse foi o padrão de beleza citado pelos entrevistados. Vale ressaltar que apenas um homem entrevistado era negro. A variável etnia não foi escolhida para análise. Além disso, os relacionamentos afetivos com pessoas do sexo oposto referiam-se ao contato social próximo, sendo a escola o principal local desses contatos e os colegas com quem conviviam nesse espaço os seus principais intermediadores.

A classe 4 foi composta predominantemente por mulheres $(31,41 \%)$ com idade acima de 50 anos e com escolarização inferior ao segundo grau. Elas não haviam utilizado preservativo na primeira relação sexual, principalmente pelo fato de terem a primeira relação sexual somente após o casamento. Além disto, mantinham relacionamento de conjugalidade havia mais de 10 anos. Essa classe tratou principalmente da importância da comunicação interpessoal na constituição do laço afetivo (ver tabela 1). Neste caso, os relacionamentos ocorreram, segundo as entrevistadas, devido ao compartilhamento de espaços sociais e ao estabelecimento de comunicação pessoal com alguém. A presença física não foi fundamental para as entrevistadas, e sim, a implicação dos envolvidos na comunicação, bem como o comprometimento daqueles com os quais se comunicavam. A comunicação, seja ela presencial (face a face) ou de forma escrita (cartas ou e-mail), foi um dos principais aspectos para a constituição da relação de proximidade e, consequentemente, de um futuro laço de conjugalidade e de confiança para as participantes.

Outro aspecto que caracterizou esta classe foi a influência dos pais no controle sobre a sexualidade, sobretudo nas narrativas das mulheres com idade superior a 50 anos. Elas revelaram que esse controle era exercido pelos pais, que só lhes permitiam sair para locais como a Igreja ou festas comunitárias.

2 exceção da classe 2 as demais serão apresentadas com o dobro da média mínima da classe, devido a delimitação do artigo. 
As classes 2 e 3 estiveram relacionadas à proteção à sexualidade. A classe $2(12,11 \%)$ foi a menos significativa e focalizou as experiências sexuais iniciais dos participantes da pesquisa e a utilização de métodos de contracepção na primeira relação sexual. A classe $3(35,39 \%)$ foi a mais expressiva das quatro e enfocou o desenvolvimento da relação conjugal e os métodos de prevenção de doenças sexualmente transmissíveis no contexto afetivo-sexual da confiança e do amor. A classe 2 foi mais associada aos participantes com mais de 10 anos de relacionamento, e a classe 3, aos homens com idade inferior a 50 anos, que tinham curso superior e utilizaram preservativo em sua primeira relação sexual.

$\mathrm{Na}$ classe 2, uma das questões ressaltadas nas respostas foi a distinção entre homens e mulheres, sobre o cuidado relativo à gravidez e sobre a prevenção à Aids. A maioria dos entrevistados revelou não haver utilizado preservativo com os parceiros atuais. Os homens, de maneira geral, delegaram a responsabilidade da prevenção à gravidez às companheiras. O preservativo, quando citado, foi utilizado como forma de prevenção à gravidez no início do relacionamento, mas foi abandonado conforme o relacionamento avançou no tempo. Nas respostas das mulheres, foi recorrente a dificuldade em utilizar métodos de prevenção ou de contracepção quando adolescentes, pois esses comprometiam a idoneidade delas perante os pais e seu grupo social. Um dos fatos que mais dificultaram a utilização de preservativo, segundo as respostas dos entrevistados, foi a imprevisibilidade do relacionamento sexual; ou seja, quanto mais o relacionamento sexual foi inesperado, menores foram as condições de prevenção, principalmente para as mulheres participantes da pesquisa. $\mathrm{O}$ cuidado com a prevenção foi tanto menor quanto mais jovens eram as entrevistadas. Este fato pode ser ilustrado pelo número de 6 entrevistadas grávidas, no universo das 24 participantes da pesquisa.

$\mathrm{Na}$ classe 3 apareceram, de forma mais significativa, respostas de homens com idade inferior a 50 anos, que tinham curso superior e haviam utilizado preservativo na primeira relação sexual. A principal diferença entre os que utilizaram preservativo e aqueles que não o fizeram foi o fato de os mais jovens terem iniciado a vida sexual num período em que a preocupação com a Aids já existia. Mesmo assim, isto não foi unanimidade nas respostas dos sujeitos entrevistados. Ainda nessa classe, foi identificado que o amor e a confiança foram formas estratégicas de prevenção à Aids. Os participantes conceberam o amor ligado a sentimentos e a ideias de "relacionamento" e "projeto de vida". Tanto os homens quanto as mulheres revelaram que confiar no parceiro foi um elemento fundamental para o que chamaram de amor. Relacionaram essa confiança ao comprometimento que um deve ter para com o outro e ao fato de os integrantes do casal apresentarem semelhanças entre si. Isso pode estar expresso nas respostas de alguns homens e mulheres que declararam acreditar que seus companheiros ou suas companheiras não os colocariam em risco se fossem ter relacionamentos com outra pessoa. Consideraram essa possibilidade como uma situação difícil de ser avaliada. Representações sociais da Aids

No segundo corpus, houve um total de 46.918 ocorrências de palavras e 4.551 palavras distintas, indicando uma média de 10 ocorrências por palavra. $\mathrm{O}$ corpus 2 foi dividido em 1.127 unidades de contexto elementares (UCEs) e a análise hierárquica descendente considerou para a análise 959 UCEs, ou seja, $85,09 \%$ do total das UCEs que esse corpus primeiramente possuía.

A figura 2 apresenta um dendograma com as duas classes obtidas mediante a análise hierárquica descendente do conteúdo das entrevistas sobre a Aids.

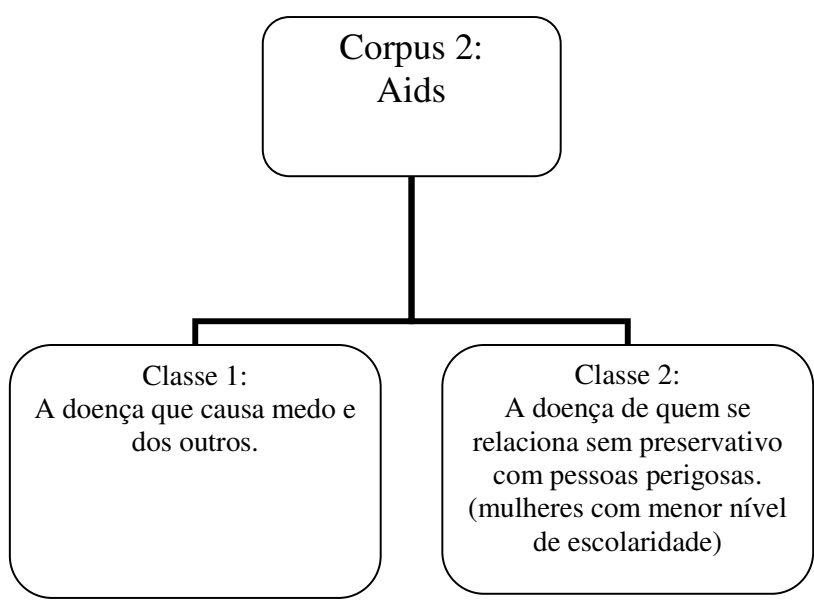

Figura 2. Classificação Hierárquica Descendente do Conteúdo das Entrevistas Sobre a Aids ( $\mathrm{n}=48)$. Florianópolis, 2006.

A classe $1(51,62 \%)$ foi a mais significativa e apresentou as respostas dos participantes quanto ao que pensavam sobre a Aids e como ela se tornou uma doença conhecida por eles. Na classe $2(48,38 \%)$ foram incluídas respostas que remeteram aos riscos que os entrevistados revelaram conhecer sobre as relações sexuais sem preservativo com pessoas que, na compreensão deles, tinham comportamentos perigosos. 
Tabela 2. Conteúdo das Classes Sobre o Tema da Aids (Síntese, nº de UCE e Palavras Associadas).

\begin{tabular}{|c|c|c|c|}
\hline Classe & Síntese & $\mathrm{UCE}(\%)$ & Palavras associadas (frequência; $\chi^{2}$ ) \\
\hline 1 & $\begin{array}{l}\text { A Aids é uma doença que causa medo e } \\
\text { morte entre as pessoas; e que se tornou } \\
\text { conhecida por meio de pessoas públicas: } \\
\text { atores, cantores e atrizes, que morreram } \\
\text { devido aos seus comportamentos. }\end{array}$ & $\begin{array}{c}495 \\
(51,62 \%)\end{array}$ & $\begin{array}{l}\text { Pessoas }(275 ; 13,86) \text {, Aids }(214 ; 54,44), \text { gente } \\
(198 ; 9,01) \text {, como }(137 ; 6,96) \text {, doença }(116 ; \\
40,53) \text {, anos }(95 ; 7,95) \text {, camisinha }(95 ; 45,06), \\
\text { risco }(78 ; 6,44), \text { vírus }(69 ; 50,38) \text {, sexo }(57 ; \\
6,85) \text {, sexual }(53 ; 4,67), \text { tem }(313 ; 18,77), \text { pode } \\
(101 ; 8,52) \text {, ser }(92 ; 0,14) \text {, são }(76 ; 10,85) \text {, } \\
\text { lembro }(51 ; 15,51) .\end{array}$ \\
\hline 2 & $\begin{array}{l}\text { A Aids é um risco que afeta as pessoas } \\
\text { que se relacionam sexualmente sem } \\
\text { preservativo com pessoas de } \\
\text { comportamento perigoso. }\end{array}$ & $\begin{array}{c}464 \\
(48,38 \%)\end{array}$ & 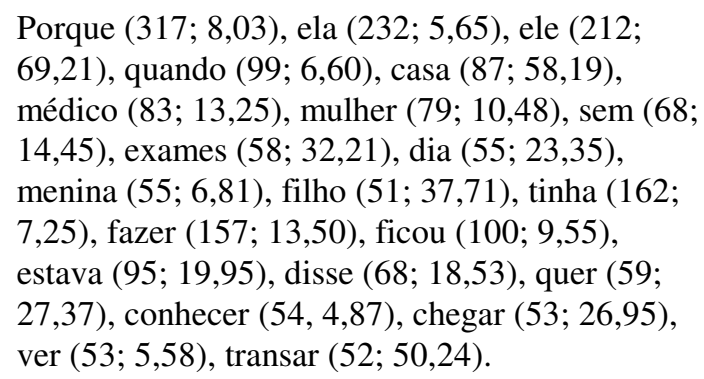 \\
\hline
\end{tabular}

A classe 1 foi formada por respostas que atrelaram a Aids à ideia de uma doença que causava medo e que acometia "gente famosa" que havia morrido devido aos seus comportamentos "desviantes". Por comportamento perigoso e desviante eles entenderam o uso de drogas, o sexo com vários parceiros e com pessoas do mesmo sexo.

Apesar de uma parte dos entrevistados, composta principalmente por aqueles com curso superior, dizer que os números da Aids mudaram sensivelmente, aqueles com menor escolaridade (ensino médio ou educação fundamental) conceberam a síndrome como uma doença ligada apenas a grupos específicos, percebidos como mais vulneráveis a essa enfermidade. Os grupos citados foram aqueles já conhecidos desde o início da epidemia: homossexuais, pessoas promíscuas e usuários de drogas. Quando solicitados a identificar uma imagem para relacionar à Aids, referiram-se a um "mal", associando-o às imagens de "diabo, tigre e serpente".

A classe 2 foi composta, sobretudo, das respostas de mulheres cuja escolaridade era inferior ao ensino superior e que não utilizaram preservativo na primeira relação sexual. Esta é uma informação importante, pois a classe que se diferenciou desta foi de homens com idade inferior a 50 anos e com curso superior. Nas respostas, foi possível identificar que o fato de estas mulheres terem iniciado a vida sexual com os parceiros com quem casaram dificultou a utilização do preservativo, ao contrário do que se verificou com os homens, os quais iniciaram sua vida sexual com pessoas que não eram suas namoradas ou com as quais não mantinham relacionamentos fixos. A classe 2 correspondeu, de forma sistemática, a uma concepção de que a Aids acometia pessoas que se relacionavam sexualmente sem preservativo com gente considerada de comportamento perigoso, ou com quem não se "conhecia". Surgiu, nessa classe, a importância do "exame" como forma privilegiada de conhecimento sobre o estado sorológico de uma pessoa; porém tanto os homens quanto as mulheres declararam ter dificuldade em fazer este teste. O exame, quando utilizado, foi um recurso para sanar uma dúvida a partir de um relacionamento considerado arriscado. Uma das estratégias utilizadas para isso foi a doação de sangue. A reprodução foi também citada nessa classe, influenciando-a, devido ao fato de a classe 2 ser predominantemente constituída de mulheres. O uso do preservativo foi relacionado às doenças - no caso, à Aids - e a pessoas “desconhecidas". A utilização da pílula foi mencionada como algo para evitar gravidez e a ser empregado com o parceiro estável ou cônjuge.

\section{DISCUSSÃO}

Os Dendogramas (Figuras 1 e 2) correlacionaramse a partir da organização dos resultados, atrelando as representações sociais da Aids ao estado afetivosexual da amostra estudada. Vale a pena especificar que os resultados são demonstrativos de um tipo de conjunto de respostas não passíveis de generalização, pelo fato de a amostra de sujeitos ter sido de 48 pessoas com idades significativamente heterogêneas, $o$ que, por sua vez se deve principalmente a que as estratificações geracionais doram bastante variáveis. 
As representações da Aids e a sua relação com os comportamentos de prevenção no interior das interações afetivo-sexuais foram fundamentais como teorias organizadoras de suas ações, principalmente quando relacionadas às concepções dos entrevistados sobre amor e conjugalidade. As respostas das pessoas entrevistadas podem ser relacionadas a outros estudos já realizados sobre a temática (Giacomozzi \& Camargo, 2003; Maia, Guilhem \& Freitas, 2008).

Quanto à transmissão do HIV, assim como observado em pesquisas anteriores, verificou-se uma responsabilidade atribuída aos mesmos grupos identificados como responsáveis pela epidemia no passado que ainda são associados ao medo e são alvo de preconceito. (Joffe, 1998; Camargo, Barbará \& Bertoldo, 2007; Garrido, Paiva, Nascimento, Sousa \& Santos, 2007). Pode-se perceber que a ancoragem da Aids foi atrelada aos grupos com sexualidade e comportamentos divergentes daqueles considerados normais e teve uma função identitária para os participantes, que viviam em relação de conjugalidade, para que pudessem se perceber mais protegidos do que outros grupos. Provavelmente, a não utilização do preservativo se deveu ao fato de as pessoas estarem vivendo um relacionamento de conjugalidade. Estes dados podem ser comparados com aqueles encontrados por pesquisas realizadas em outros países por Apostolidis e Deschamps (2003) e Monteiro (2009), em que o relacionamento afetivo-sexual conferiu grau de segurança aos entrevistados. É possível pensar que o fato de os participantes da pesquisa não usarem preservativo teve relação com o desejo de viver junto, característica do roteiro conhecido como enlace amoroso (Valencia-Abundiz, 2004). Além disto, foi crucial para a não utilização do preservativo nos relacionamentos de conjugalidade o fato de as mulheres terem a responsabilidade da usar o contraceptivo oral. Este faz com que o preservativo seja pouco a pouco abandonado como estratégia de prevenção da gravidez. (Heilborn, Portella, Brandão \& Cabral, 2009)

Os resultados desta pesquisa trouxeram dados equivalentes a outras que abordaram temáticas semelhantes tanto no campo dos estudos sobre Aids quanto daqueles relativos às representações sociais. Tanto os homens quanto as mulheres entrevistadas consideraram não existir risco na relação com os (as) parceiros (as). Esta negação do risco também foi identificada em outras pesquisas sobre a temática. (Oltramari \& Otto, 2006, Saldanha, Carvalho, Diniz, Freitas, Félix \& Silva, 2008, Doron, Teichner, Grey \& Goldstein, 2008) Isto quer dizer que existiu, entre os entrevistados, uma lógica que apontou os parceiros como isentos de risco na relação com o HIV. Estes dados também têm se mostrado significativos com relação à autoatribuição do risco de contrair o HIV. Mesmo com o conhecimento sobre os riscos de infecção pelo HIV, a autoatribuição não se apresentou relevante entre parceiros sexuais com relações estáveis no momento da entrevista (Saldanha, Carvalho, Diniz, Freitas, Félix \& Silva, 2008; Ferreira, 2008).

Não foi possível identificar se isto foi ocasionado por diferenças de conhecimento significativas entre os entrevistados com distintos níveis de formação, como em pesquisa de Rahman e Rahman (2007). Também não apareceu nesta pesquisa diferença entre formas de conhecimento sobre o HIV entre homens e mulheres como na pesquisa de Wong, Chin, Low e Jaafar (2008)

A concepção que opõe Aids de um lado e amor e conjugalidade do outro deu-se, em parte, em virtude de um "estranhamento" em relação a essa doença, pelo fato de seu surgimento estar atrelado a grupos específicos (Joffe, 1998, Saldanha, Carvalho, Diniz, Freitas, Félix \& Silva, 2008). Nos resultados pôde-se compreender que a conjugalidade apareceu desempenhando uma função justificatória para a não utilização do preservativo nas relações sexuais. Com esta justificativa os participantes mantiveram um controle imaginário sobre a síndrome, já que esta foi ancorada na imagem de doença que acometia, na compreensão dos entrevistados, pessoas "descuidadas ou de comportamento perigoso". A confiança foi o elemento fundamental para a constituição do amor conjugal por grande parte dos entrevistados. A ideia de confiança também foi observada nas pesquisas de Giacomozzi e Camargo (2003) e Knauth, Víctora e Fachel (2006).

Nesta pesquisa, até onde os dados nos permitiram chegar, foi possível compreender a "confiança" não como uma demonstração irresponsável de crença no sujeito, mas como uma aposta na direção do futuro do relacionamento conjugal, baseada em uma relação de reciprocidade que dava estabilidade ao relacionamento. Dessa forma, a Aids apareceu como um elemento exterior ao relacionamento de conjugalidade, que o colocava em situação de desestabilização. Assim, o risco de contrair o HIV põde ser considerado menor, pelos entrevistados, do que o de colocar em jogo seu relacionamento afetivosexual.

Os participantes atrelaram a Aids a pessoas que se relacionavam sem preservativo e apresentavam comportamento considerado perigoso. Com isso, os participantes que estavam em uma relação conjugal justificaram suas ações não preventivas, já que se 
encontravam, em sua concepção, protegidos no interior do relacionamento conjugal. Este foi considerado, pela quase totalidade dos entrevistados, como mais seguro do que outros relacionamentos. Não houve diferenças estatisticamente significativas nas opiniões entre homens e mulheres. O que houve foi que as mulheres citaram mais a traição como algo que poderia trazer risco de infecção nos relacionamentos conjugais; já os homens pouco citaram esta possibilidade. Isto pode ser atribuído às diferenças de gênero e condutas sexuais que existem ainda em nossa sociedade, pois as pesquisas demonstram que, mesmo com as mudanças significativas que vêm ocorrendo sobre as práticas sexuais de homens e mulheres, ainda os homens encontram legitimidade maior para terem relacionamentos extraconjugais. (Jaspard, 2005).

\section{CONSIDERAÇÕES FINAIS}

É possível identificar, por meio das respostas dos participantes, que houve, em seus sistemas simbólicos de representação, uma forte ligação da Aids a pessoas que apresentam comportamentos considerados "arriscados", e esta lógica afastou a Aids do universo dos participantes da pesquisa. Estar em conjugalidade foi uma forma de se julgarem protegidos do HIV.

Assim, as representações sociais da Aids estruturaram-se em uma relação de oposição entre "conhecido/seguro/ confiante" versus "desconhecido/ inseguro/perigo". Essa dicotomia foi extremamente importante para a não utilização do preservativo nas relações de conjugalidade. Vale ressaltar que não houve diferenças significativas nas variáveis (idade, por exemplo) entre homens e mulheres, que justificassem estas respostas. A utilização de preservativo se deu mais por conta de um cuidado com pessoas que são desconhecidas e com a prevenção à gravidez, no caso de parceiro conjugal.

Foi possível identificar com este estudo que, mais do que uma "não percepção" sobre suas condições reais de vulnerabilidade, existe uma forma prática, que fez com que os participantes organizassem suas ações a partir das representações sociais da Aids. As entrevistas revelaram que, quando a conjugalidade é institucionalizada, existe uma ideia de prevenção atrelada ao parceiro que é conhecido e que não vai expor o outro ao risco. Esta lógica de pensamento foi muito importante para a compreensão da não utilização de preservativo nas relações conjugais. Percebeu-se que, mais do que estar na relação de conjugalidade, foram importantes o tempo de contato com o envolvido na relação sexual e a possibilidade de confiança nele. Assim, quanto mais tempo as pessoas tinham de proximidade ou contato pessoal, menor foi a capacidade de exigir o uso de preservativo, tanto para homens quanto para mulheres.

Ficam aqui, no fim deste estudo, alguns questionamentos para as políticas públicas em saúde. Como fazer prevenção com o uso do preservativo entre aqueles que vivem em regime de conjugalidade e que apresentam as características detalhadas na pesquisa? Como sensibilizar essas pessoas a construírem práticas sexuais mais seguras dentro desses contextos relacionais?

Ao que parece, devem ser realizados outros estudos desse tipo, com outras metodologias e características populacionais, para que essas perguntas obtenham resposta.

\section{REFERÊNCIAS}

Apostolidis, T. \& Deschamps, J.-C. (2003). Une Approche Psychosociale De L'amour: Logiques normatives et représentations. Nouvelle Revue de Psychologie Sociale 2(2), 216-227.

Camargo, B. V., Barbara, A. \& Bertoldo, R. B. (2007) Concepção pragmática e científica dos adolescentes sobre a AIDS. Psicologia em estudo, 12(2), 277-284.

Camargo, B.V. (2005). ALCESTE: um programa informático de análise quantitativa de dados textuais. Em A. S. P. Moreira; B.V. Camargo; J. C. Jesuíno \& S. M. Nóbrega. (Org) Perspectivas teórico-metodológicas em representações sociais. (pp. 511-540). João Pessoa: Editora Universitária.

Doron, H. Teichner, N, Grey, A. Goldstein, Y. (2008) "Contagious Love": A Qualitative Study of the Couple Relationships of Ten AIDS Carriers. The Open AIDS Journal, 2, 58-67

Ferreira, M. P. (2008) Nível de conhecimento e percepção de risco da população brasileira sobre o HIV /Aids, 1998 e 2005. Revista Saúde Pública; 42(Supl 1) 65-71

Gagnon, J. (2006). Uma interpretação do desejo: ensaios sobre o estudo da sexualidade. Rio de Janeiro: Garamond.

Garrido, P., Paiva, V., Nascimento, V., Sousa, J. \& Santos, N. (2007) Aids, estigma e desemprego: implicações para os serviços de saúde. Revista de Saúde Pública, 41(Supl. 2)72-9

Giacomozzi, A. I. \& Camargo, B. V. (2003). Eu confio no meu marido: estudo da representação social de mulheres com parceiro fixo sobre prevenção da AIDS. Psicologia: teoria e prática, 1(6), 31-44.

Heilborn, M. L. Portella, Portella, A. P., Brandão, E. R. \& Cabral, C. da S. (2009). Assistência em contracepção e planejamento reprodutivo na perspectiva de usuárias de três unidades do Sistema Único de Saúde no Estado do Rio de Janeiro, Brasil. Cadernos de Saúde Pública 25(supl.2), 269-278 .

Heilborn, M. L.(2004). Dois é par: gênero e identidade sexual em contexto igualitário. Rio de Janeiro: Garamond.

Jaspard, M. (2005). Sociologie des comportements sexuels. Paris: La decouverte. 
Joffe, H. (1998) “Eu não', ‘o meu grupo não”: representações sociais transculturais da Aids". Em P. A. Guareschi \& S. Jovchelovitch. (Orgs.). Textos em representações sociais. (pp. 297-322). Petrópolis: Vozes.

Knauth, D.R., Víctora, C.G., Leal, AF. \& Fachel, J. (2006) As trajetórias afetivos-sexuais: encontros, uniões e separação. Em M. L. Heilborn, E. M. L. Aquino, M. Bozon \& D. R. Knauth. (Orgs). $O$ aprendizado da sexualidade: reprodução e trajetórias sociais de jovens brasileiros. (pp.269-310), Rio de Janeiro: Garamond/Fiocruz.

Maia, C.; Guilhem, D \& Freitas, D. (2008) Vulnerabilidade ao HIV /Aids de pessoas heterossexuais casadas ou em união estável. Revista de Saúde Pública; 42(2), 242-8

Ministério da Saúde. (2005) Boletim Epidemiológico, 2006. Boletim Epidemiológico - Aids e DST. Ano II - no 1 - 01 a - $26^{\mathrm{a}}$ de 2005 semanas epidemiológicas. Janeiro a junho de 2005.

Monteiro, S. (2009). STD/AIDS prevention in Portuguese-speaking Africa: a review of the recent literature in the social sciences and health. Caderno Saúde Pública, Rio de Janeiro, 25(3), 680-686.

Oltramari, L. C. \& Otto, L. S. (2006) Conjugalidade e aids: um estudo sobre infecção entre casais. Psicologia \& Sociedade; 18(3), 55-61.

Paiva, M. S.\& Amâncio, L. (2005) Implicações das representações sociais na vulnerabilidade de gênero para sida/Aids entre jovens universitários: estudo comparativo Brasil - Portugal. Em III Jornada internacional de representações sociais - João Pessoa/PB. (Orgs) IV Jornada Internacional e II Conferência Brasileira Sobre Representações Sociais,( pp. 3106-3125) João Pessoa: UFPB.
Rahman, M. S. \& Rahman, M. L. (2007). Media and education play a tremendous role in mounting AIDS awareness among married couples in Bangladesh. AIDS Research and Therapy, 4(10), 1-7.

Ribeiro, C. G., Castanha, A. R., Coutinho, M. P. L. \& Saldanha, A. A. W. (2005) A Aids e suas contradições: representações sociais de seu atendimento e tratamento pelos profissionais e pacientes. DST - Jornal Brasileiro de Doenças Sex Transmissão, 2(17), 127-132.

Saldanha, A. A. W., Carvalho, E.A.B, Diniz, R.F, Freitas, E. S, Félix, S. M. F. \& Silva, E. A. A. (2008) Comportamento sexual e vulnerabilidade à aids: um estudo descritivo com perspectiva de práticas de prevenção. Jornal brasileiro de Doenças Sexualmente Transmissiveis; 20(1), 36-44

Valencia-Abundiz, S. (2004) Representations Sociales: image ideale et vecu de la relation de couple. These doctorat: Psicologie Sociale. Ecole de Hautes Etude en Science Sociale, Paris.

Wong, Li-Ping, Chin, C-K L., Low W-Y \& Jaafar, N. (2008). HIV /AIDS-Related Knowledge Among Malaysian Young Adults: Findings From a Nationwide Survey. Journal of the International AIDS Society, 10(148), 1-9.

Recebido em 12/01/2009 Aceito em 16/12/2009

\section{Endereço para correspondência:}

Brígido Vizeu Camargo. Departamento de Psicologia, Campus Universitário Trindade, Bloco C, $2^{\circ}$ piso, CEP 88.040-900, Florianópolis-SC, Brasil. E-mail: brigido.camargo@ yahoo.com.br. 